\title{
Pneumocystis jirovecii-from a commensal to pathogen: clinical and diagnostic review
}

\author{
Magdalena Sokulska $^{1} \cdot$ Marta Kicia $^{1} \cdot$ Maria Wesołowska $^{1} \cdot$ Andrzej B. Hendrich $^{1}$ (D)
}

Received: 5 August 2015 / Accepted: 7 August 2015 /Published online: 19 August 2015

(C) The Author(s) 2015. This article is published with open access at Springerlink.com

\begin{abstract}
Pneumocystis pneumonia is an opportunistic disease caused by invasion of unicellular fungus Pneumocystis jirovecii. Initially, it was responsible for majority of morbidity and mortality cases among HIV-infected patients, which later have been reduced due to the introduction of anti-retroviral therapy, as well as anti-Pneumocystis prophylaxis among these patients. Pneumocystis pneumonia, however, is still a significant cause of mortality among HIV-negative patients being under immunosuppression caused by different factors, such as transplant recipients as well as oncologically treated ones. The issue of pneumocystosis among these people is particularly emphasized in the article, since rapid onset and fast progression of severe symptoms result in high mortality rate among these patients, who thereby represent the group of highest risk of developing Pneumocystis pneumonia. In contrast, fungal invasion in immunocompetent people usually leads to asymptomatic colonization, which frequent incidence among healthy infants has even suggested the possibility of its association with sudden unexpected infant death syndrome. In the face of emerging strains with different epidemiological profiles resulting from genetic diversity, including drug-resistant genotypes, the colonization phenomenon desires particular attention, discussed in this article. We also summarize specific and sensitive methods, required for detection of Pneumocystis invasion and for distinguish colonization from the disease.
\end{abstract}

Keywords Pneumocystis jirovecii · Pneumocystis pneumonia $\cdot$ Opportunistic infection $\cdot$ Colonization

Andrzej B. Hendrich

andrzej.hendrich@umed.wroc.pl

1 Department of Biology and Medical Parasitology, Wrocław Medical University, ul. Mikulicza-Radeckiego 9, 50-367 Wrocław, Poland

$\begin{array}{ll}\text { Abbreviations } \\ \text { PcP } & \text { Pneumocystis pneumonia } \\ \text { DHFR } & \text { Dihydrofolate reductase } \\ \text { DHPS } & \text { Dihydropteroate synthase } \\ \text { HAART } & \text { Highly active anti-retrovirus therapy } \\ \text { SNP } & \text { Single-nucleotide polymorphism } \\ \text { MLST } & \text { Multilocus sequence typing } \\ \text { BG } & (1 \rightarrow 3)-B-D-g l u c a n \\ \text { LDH } & \text { Lactate dehydrogenase } \\ \text { TMP-SMX } & \text { Trimethoprim-sulphamethoxazole }\end{array}$

Pneumocystis spp. are unicellular, eukaryotic organisms occurring in lungs of many mammals. Five species-specific Pneumocystis species have been identified: Pneumocystis carinii and Pneumocystis wakefieldiae in rats, Pneumocystis murina in mice, Pneumocystis oryctolagi in rabbits, and Pneumocystis jirovecii in humans (Aliouat-Denis et al. 2008). P. jirovecii is a causative agent of Pneumocystis pneumonia (PcP; pneumocystosis), a particularly hazardous disease in case of people with impaired immune system. In immunocompetent people, infection caused by this pathogen may also lead to an asymptomatic carriage, which is an undesirable phenomenon, due to its contribution to Pneumocystis dissemination in population.

\section{Brief history}

Pneumocystis, initially considered to be a protozoan, later has been assigned to the kingdom of fungi, due to its high genetic sequence homology with these organisms, as demonstrated by molecular studies (Edman et al. 1988). Nevertheless, despite many similarities, Pneumocystis is an atypical fungus which differs in several respects from its relatives. One of such 
distinctive features, among others, is the presence of cholesterol in the Pneumocystis cell membrane, instead of ergosterol, which is the target of amphotericin B and ketoconazols. Therefore these drugs, commonly used as therapeutics in infections caused by other fungi, are ineffective in treatment of symptoms triggered by $P$. jirovecii (Kaneshiro et al. 1994).

Further DNA analyses have revealed that Pneumocystis species infecting lungs of various mammalian species are quite different and their infection is host specific - for example, individuals taken from rats and transferred to mice will not proliferate nor cause any symptoms of infection, while transmission to another rat will cause severe disease (Aliouat et al. 1994). After this discovery, P. jirovecii, formerly Pneumocystis f. sp. hominis, has been identified as a separate subspecies characteristic for humans. The name was given in honor of the Czech parasitologist Otto Jirovec, due to his important contribution in describing this organism in humans (Frenkel 1999).

\section{Structure and life cycle}

Pneumocystis spp. has a biphasic life cycle with two distinct morphological forms: haploid trophozoites, constituting the proliferative stages, being asexual phase of the lifecycle, and cysts, representing a reproductive stage. Cysts are generated during the sexual phase, as a result of conjugation of trophozoites (Limper and Thomas 2007). Trophic forms predominate in lungs during the infection, while cysts have the major role in Pneumocystis propagation (Dumoulin et al. 2000).

\section{Pneumocystis pneumonia}

Transmission of $P$. jirovecii cysts takes place through the airborne route, and usually, its presence in lungs is asymptomatic. However, people with impaired immunity, especially those with CD4+ T cell count below 200/ $\mu 1$ (Phair et al. 1990), are still at risk of the development of Pneumocystis pneumonia due to $P$. jirovecii invasion. Symptoms induced by this disease are not specific: progressive dyspnoea, non-productive cough, low-grade fever, arterial partial pressure of oxygen below $65 \mathrm{mmHg}$, and chest radiographs demonstrating bilateral, interstitial shadowing (Barry and Johnson 2001). In computed tomography (CT) examination, the initial appearance of $\mathrm{PcP}$ is characterized by ground glass opacities, which are considered to disappear after introducing adequate therapy. Therefore, CT observations may also be useful while monitoring the effectiveness of treatment (Vogel et al. 2012). Moreover, it has been shown that the early stages of $P$. jirovecii proliferation induce alveolar macrophages activation and an increase of proinflammatory interleukins level, as well as changes in pulmonary surfactant. These anatomical and physiological changes may occur even during infection characterized by low fungal burden (Limper et al. 1989).

First cases of Pneumocystis pneumonia were observed in the 1960 s, as an ailment caused by the presence of opportunistic pathogen in children with congenital $\mathrm{T}$ cell immunodeficiency, as well as in patients with hematological neoplasm (Walzer et al. 1976). The incidence of this disease markedly decreased after introducing anti-Pneumocystis chemoprophylaxis, but it has increased again after emergence of human immunodeficiency virus (HIV) in 1980s. PcP has been one of the main causes of morbidity and mortality among HIV-infected people and has been the most common AIDS-defining opportunistic infection in USA, developing in more than $60 \%$ of patients during their disease course (Selik et al. 1987). PcP among those patients was characterized by a significant level of Pneumocystis proliferation, whereas the inflammatory reaction was weak. The PcP incidence has decreased again after introducing highly active anti-retrovirus therapy (HAART) and routine use of anti-PcP prophylaxis, as well as due to improved awareness of this infection among medical care workers (Kaplan et al. 2000). This decline demonstrates substantial restoration of the immune system due to HAART, which raises the $\mathrm{CD} 4+\mathrm{T}$ cell level and thereby protects patients against opportunistic infections. PcP, the most common of such complications, still occurs primarily in patients deprived of medical care or unaware of their HIV status (Kaplan et al. 2000; Stringer 2002). There are also cases of PcP among patients already receiving prophylaxis, probably due to low adherence, poor performance at a very low CD4+ T cell counts or infection with resistant HIV strains (Kaplan et al. 2000).

Another group of patients which are still at high risk of infection are non-HIV individuals with immunodeficiency caused by receiving cytotoxic and immunosupressive therapy for solid tumors, hematological malignancies or inflammatory and rheumatic diseases, as well as organ transplant recipients (Li et al. 2014). Increased number of cases of PcP in this group may be related to greater frequency of applications of immunosuppressants, usage of their higher doses, or to different combination of immunsuppressive agents which lead to enhanced susceptibility of patient to Pneumocystis infection (Ward and Donald 1999). In addition, due to improvements in medical care, more people with immune deficiency survive, remaining at risk of PcP. On the other hand, non-HIV patients are less aware that they are at risk of PcP, which often contributes to prolonged time from the onset of symptoms to treatment initiation. Thus, this group of patients represents a novel, serious public health care problem (Fig. 1).

\section{Non-HIV patients - the group of highest risk}

It has been shown that PcP in non-HIV patients is characterized by more rapid onset and faster progression of symptoms, which are also more serious than in HIV-infected individuals. 


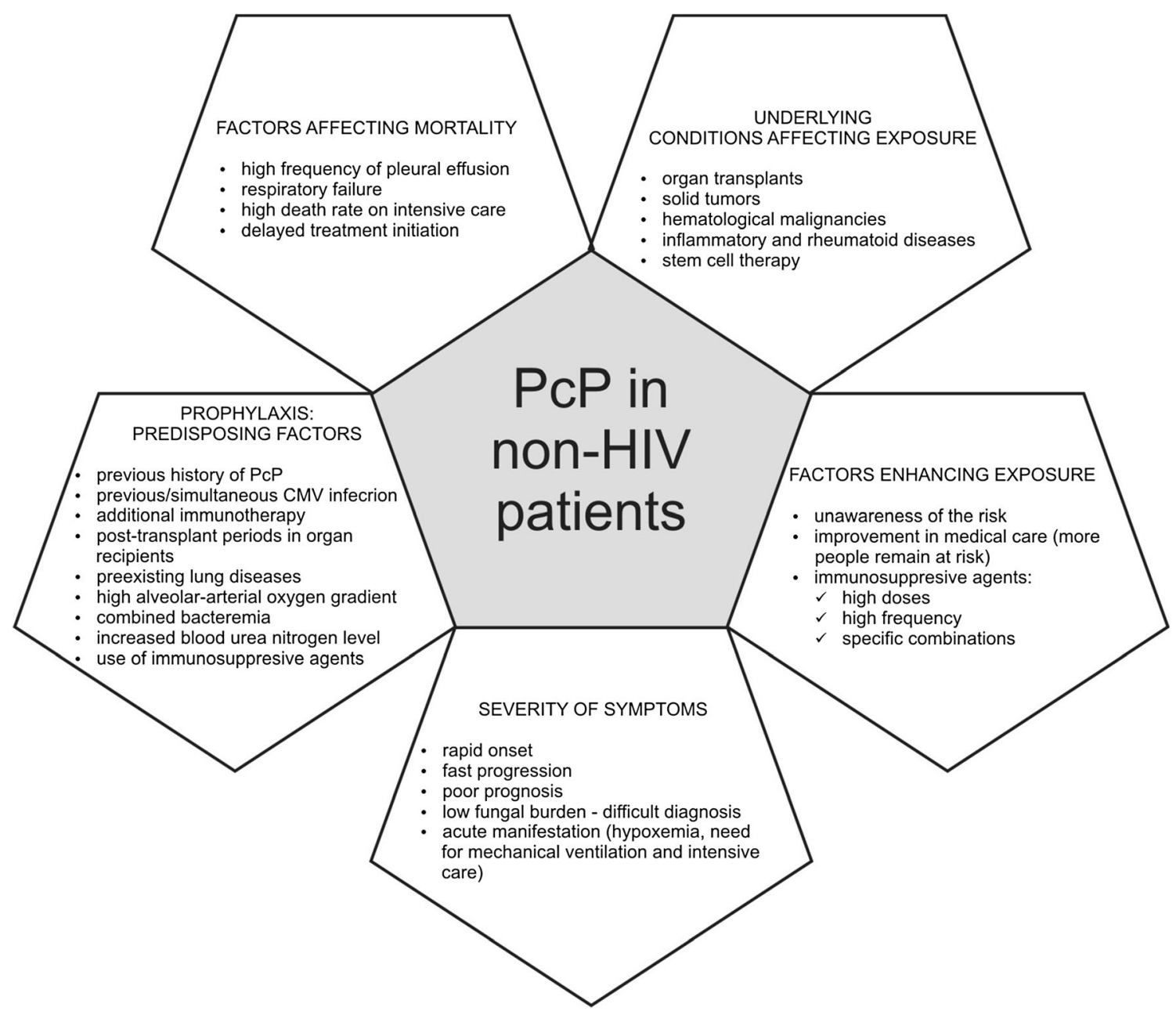

Fig. 1 Major issues related to PcP in non-HIV patients

These symptoms include severe hypoxemia as well as greater need for intensive care and mechanical ventilation, which are often associated with poorer prognosis (Roblot et al. 2002). Therefore, death rates in this group of patients are significantly higher than in HIV-infected people, who present, in contrast, subacute disease course (Roux et al. 2014). The reason of this difference may be related to underlying condition: besides mortality, also proportion of cases requiring mechanical ventilation is higher in non-HIV than HIV-positive patients. Greater neutrophil count observed in non-HIV patients' bronchoalveolar lavage fluids suggests that lung injuries caused by $\mathrm{PcP}$ are much more severe in these cases than in HIV patients (Monnet et al. 2008).

The most significant risk factor for PcP development in non$\mathrm{HIV}$ immunosuppressed patients is the reduction of CD4+ T cell level, caused by the action of immunosuppressive agents, particularly cyclosporine A, antithymocyte globulin, as well as antirejection therapy for organ transplant recipients with high doses of glucocorticosteroids. Their effect disrupt host defense against $P$. jirovecii, which involves series of interactions between CD4+ $\mathrm{T}$ lymphocytes and polymorphonuclear cells, macrophages and proinflammatory mediators released by these cells. Therefore, depletion of CD4+ $\mathrm{T}$ cells inhibits proper reaction of immunity system (De Boer et al. 2011).

The study of Kofteridis et al. (2014), aimed to explore predisposing factors and clinical picture in non-HIV-infected people, has revealed that among this group of patients, the clinical parameters of PcP did not depend on the type of administered immunosuppression, although the risk of developing $\mathrm{PcP}$ is raised after rituximab therapy (DęborskaMaterkowska et al. 2014) or when the therapy consists of steroids together with cytotoxic agents. However, some data suggest that even malignancy itself can increase the PcP onset probability (Stapleton et al. 2015). Moreover, this paper demonstrated high frequency of pleural effusion in non-HIV patients with PcP, especially those with malignancies. Also, the mortality rate was the highest among individuals with solid tumors (Kofteridis et al. 2014). Though the death rate is associated with underlying diseases, the major factor influencing the prognosis of $\mathrm{PcP}$ is the development of respiratory failure. As compared with people infected with HIV, the death rates on intensive care unit for non-HIV patients are higher, as well as 
the necessity of implementing first-line non-invasive mechanical ventilation, which fails in a large proportion of these individuals (Monnet et al. 2008). Importantly, it is not the respiratory distress itself that causes death but the ensuing multiorgan failure (Stapleton et al. 2015).

Similar analyses performed by Kim et al. (2014) have demonstrated that in-hospital mortality was associated with factors such as high alveolar-arterial oxygen gradient, increased blood urea nitrogen level, preexisting lung disease, as well as combined bacteremia, which is also assumed to be an indirect marker of the severity of immunosuppressive status and susceptibility to PcP. Higher mortality rate has also been observed in patients requiring mechanical ventilation (Ko et al. 2014).

Another risk factor for $\mathrm{PcP}$ is previous or simultaneous cytomegalovirus (CMV) infection. This virus suppresses helper $\mathrm{T}$ and antigen presenting cells' functions, thereby altering host immune response. Therefore, diagnosis of one opportunistic infection in susceptible patient, such as transplant recipient, suggests the possibility of existence of another one. Re-introduction of PcP prophylaxis is suggested whenever a patient is recognized with CMV infection or treated with additional immunosuppressive therapy for acute rejection episode after transplantation, due to heavier burden of immunosuppression in such cases. Moreover, prolonged prophylaxis is advisable for patients with a previous history of $\mathrm{PcP}$ (Borstnar et al. 2013).

\section{Transmission and colonization}

Since the antibodies against $P$. jirovecii were found in majority of children under the age of 4 (Piffer et al. 1978), it has been initially assumed that PcP development is mostly derived from latent Pneumocystis infection, acquired in early life. The subsequent genotypic analysis have shown, however, that the primary infection may be cleaned in immunocompetent hosts, and the PcP is caused by re-infection with different strains, typical for place of residence rather than place of birth (Keely et al. 1995).

The transmission of Pneumocystis occurs via an airborne route. It has been demonstrated that immunocompetent hosts could serve as a reservoir of the fungus in population through transferring it from one individual to another when they are within sufficiently close distance, without causing symptomatic disease, until the pathogen reaches the immunocompromised host, in which PcP may develop (Gigliotti et al. 2003). Data obtained from experiments on mice and rats indicate that close-contact period as short as 1 day is enough to transmit infection from donors to immunocompetent carriers, which can carry low numbers of pathogen for a relatively long time, thereby contributing to Pneumocystis circulation in the population (Dumoulin et al. 2000). It is noteworthy that asymptomatic carriage is a transient event, rather than lifelong latency.
This inference seems to be supported by the observation of the pathogen presence in HIV-positive patients after PcP for no longer than 9.5 months (Wakefield et al. 2003).

Asymptomatic carriage of Pneumocystis is a phenomenon known as colonization and is important for several reasons. Besides transmission of the pathogen to other people, colonized individuals are also at risk of $\mathrm{PcP}$ development in case of decreased immunity. Furthermore, colonization in individuals receiving anti-Pneumocystis prophylaxis for a long time may lead to selection of drug-resistant strains. Finally, even minor amounts of pathogen present in lungs may provoke host inflammatory response, which in turn leads to lung damage and plays a role in progression of lung disorders, such as chronic obstructive pulmonary disease or lung cancer (Probst et al. 2000). Colonization has been recognized in non-HIV immunosuppressed patients, who are particularly prone to become carriers, as well as in people with more subtle immunodeficiency, such as pregnant women or people with lung diseases (Vargas et al. 2003). Thus, pulmonary disorders may be both predisposing factors for Pneumocystis colonization, as well as conditions resulting from pathogen carriage. Taking into account that people with lung tissue defects are sputum producers, their colonization may be particularly risky due to their potentially enhanced ability to infection dissemination (Rivero et al. 2008).

Another issue associated with colonization is the difficulty in differentiating it from PcP during diagnosis. Detection methods utilized in most laboratories involve molecular techniques, but the standard cutoff value to distinguish colonization from active pneumocystosis has not been established yet. Therefore, when colonized patient experiences pneumonia with a different etiology, positive results of Pneumocystis detection may be misleading (Tasaka et al. 2014).

\section{Primary Pneumocystis infection in infants}

As it was mentioned above, Pneumocystis infection/ colonization occurs frequently among healthy children. Their common exposure to primary infection is suggested by the increased level of antibodies directed against Pneumocystis recorded during the first years of life. Yet, before they develop the properly functioning immune system for total elimination of the pathogen, they may transmit it to other susceptible hosts (Vargas et al. 2001). Molecular typing studies have demonstrated that identical fungal genotypes were harbored by children and adults with PcP, living in the same area (Totet et al. 2004). This finding is clearly showing the role of colonized infants in pathogen transmission. Additionally, the colonization in children appears to be frequent phenomenon during upper respiratory infections (Spencer et al. 2009).

Recent studies indicate that $P$. jirovecii infection in children occurs most frequently in the age range from 2 to 5 months, 
which overlaps with the most common age at which the increase in respiratory morbidity is observed (Vargas et al. 2013). In nasopharyngeal aspirates, taken from infants below 2 years of age presenting with mild respiratory symptoms, $P$. jirovecii DNA was detected in one third of cases. Positive samples were detected for the significantly younger age, yet, no specific symptoms of infection were perceived (Djawe et al. 2010a). It is presumed that colonization in infants may be associated with such disorders as bronchiolitis or even sudden unexpected infant death (SUID). Despite the fact that the results of autopsies performed on children have not demonstrated any significant difference in Pneumocystis prevalence between unexpected and explained death, its high incidence among SUID victims suggests that this pathogen still may be necessary, but not the sole, causative agent of the children unexpected death phenomenon (Vargas et al. 2007).

\section{Genetic diversity}

Drug resistance of some $P$. jirovecii strains, responsible for failure of prophylaxis and/or treatment of infection, results often from the polymorphisms of different fungal genes (Kazanjian et al. 1998). Such genetic changes may also influence the epidemiological profiles of $P$. jirovecii, like pathogenicity or modes of transmission, as well as clinical outcome of PcP cases (Esteves et al. 2008). It has been shown that specific single-nucleotide polymorphisms (SNPs) in Pneumocystis genes were correlated with specific parameters of infection, such as fungal burden or type of progression and outcome of the disease (Esteves et al. 2011). Thus, molecular methods seem to be a perfect tool to study the genetic diversity among $P$. jirovecii individuals. In the future, analysis of the correlation between these different genotypes and a specific clinical picture caused by their invasion may be used to predict the PcP development, as well as to facilitate the decision about treatment and prophylaxis.

Genetic diversity of $P$. jirovecii strains is principally caused by gene variations resulting from SNPs presence. Several polymorphisms are regarded as highly informative markers for comparative analyses between the given genotype and a specific clinical or epidemiological data. For instance, it has been reported that SNP at the 85 position of the $P$. jirovecii mitochondrial large-subunit rRNA ( $m t L S U$ rRNA) gene, involved in basic mechanisms during translation, is useful to detect intraspecific differences between populations (Beard et al. 2000), whereas mutations in dihydropteroate synthase (DHPS) gene, presumably resulting from previous exposure to sulfa drug prophylaxis, have been linked to drug resistance and failure of anti-PcP treatment (Bento et al. 2013). In turn, data obtained during studies on mutations in the gene encoding DHFR enzyme from folic acid pathway demonstrate that five out of the six mutations conserved among unrelated species are located within the presumed active site of the enzyme. This observation allows the inference that SNPs distribution in this gene is not totally random, and they may have emerged by the exerted selective pressure of DHFR inhibitor, utilized in anti-Pneumocystis therapy. The outcome of this pressure is the acquisition of drug resistance, which can be observed as the failure of prophylaxis in patients infected with such strains. This effect seems to occur in response to mutations causing modifications in the enzyme's structure, thereby diminishing its affinity for inhibitors (Nahimana et al. 2004).

Multilocus sequence typing (MLST) is considered to be a gold standard for analysis of genetic diversity, as it offers many advantages: reproducibility, possibility of exchanging data from different laboratories, as well as observations of polymorphisms at many loci together, at the same time. Maitte et al. (2013) have proposed the reduced MLST scheme, utilizing the three-locus analysis: $S O D$ (superoxide dismutase), $C Y B$ (cytochrome B), and $m t L S U$ rRNA. This scheme is more economical and easier to perform, at the same time preserving the sufficient discriminatory power. Thus, it is proposed to be used in many laboratories as an alternative strategy for preliminary investigations of PcP outbreaks. It can also detect infections of single patient by two, or even more, $P$. jirovecii isolates, which has been reported to be a common event.

Determination of the genotype by following the analysis of SNPs at single locus is much less sensitive and precise comparing with MLST. Multilocus analysis not only provides more comprehensive information, it can also be used to investigate epidemiological diversity. For instance, it has been used to define the epidemiological variability, suggesting differences in genotype frequencies between Old and New World $P$. jirovecii isolates caused by geographical component (Monroy-Vaca et al. 2014). The epidemiological factors, like geographical and climatic characteristics, may also have an impact on the circulation of specific $P$. jirovecii genotypes within designated areas (Esteves et al. 2008; Dimonte et al. 2013). The geographical variation in the prevalence of gene mutations associated with drug resistance may be caused by differences in the types of PcP prophylaxis used in various regions (Esteves et al. 2008). Such epidemiological factors are yet another aspect of risk connected with colonization and transmission of different $P$. jirovecii strains (Beard et al. 2000).

\section{Detection of $P$. jirovecii and PcP diagnosis}

The rapid diagnosis of $\mathrm{PcP}$ is crucial especially among nonHIV patients due to the severe symptoms, which could be avoided by early enough implementation of treatment, since it has been shown that acceleration of treatment initiation by only one day can be associated with significantly reduced mortality (Roux et al. 2014). However, low fungal burden, 
specific for samples taken from non-HIV patients with PcP, often hinders the detection of infection and may lead to falsenegative results. It is particularly difficult to set the right diagnosis in such case using solely the gold standard - microscopic visualization of Pneumocystis, which additionally depends on skills and experience of the observer (Limper et al. 1989). Furthermore, another feature differentiating Pneumocystis species from other fungi is the lack of appropriate systems for in vitro culturing, which hinders the research on this organism even more (Stringer 2002). Therefore, diagnostic methods based on both microscopic observations and genotyping are involved.

Conventional staining methods can be used for microscopic observation of $P$. jirovecii, as well as indirect immunofluorescence staining with monoclonal antibodies directed against $P$. jirovecii cysts, which is faster and unambiguous. However, such visualizations have some limitations. First of all, they are conducted on specimens collected during sputum induction which may not be tolerated by some patients, or bronchoalveolar lavage (BAL) specimens and lung biopsies, which are invasive methods. In addition to that, histological detection relies mainly on the experience of the observer and is timeconsuming. Finally, low fungal burden, impeding the microscopic observation especially in non-HIV patients' cases, may lead to false-negative diagnosis (Limper et al. 1989).

Therefore, detection of Pneumocystis DNA whereby PCR assays amplifying various genetic fragments has been implicated. The sensitivity of diagnosis can be improved either due to application of multicopy gene target, like $m t L S U r R N A$ or $m s g$, or by using nested PCR that consists of two rounds of amplification, thereby increasing detection rate (AlvarezMartínez et al. 2006). Introduction of PCR method has revealed the new population of people with detectable Pneumocystis DNA, even though just few or no organisms are visualized (Peterson and Cushion 2005). Widespread use of conventional PCR method in clinical practice has one limitation, namely insufficient specificity and lack of quantification, required for distinguishing between $\mathrm{PcP}$ and colonization. The improved version of the PCR assay has emerged, which possess those advantageous features - quantitative realtime PCR (qRT-PCR). It is also beneficial over the nested PCR, due to limitation of the risk of DNA carry-over and reduction of time consumption, as it is a one-step process (Alanio et al. 2011). However, interpretation of the results is still ambiguous and standard quantities to set the right diagnosis and differentiate $\mathrm{PcP}$ from colonization have not been determined yet. Besides, the remaining impediment is the invasiveness of BAL performance, which is impossible in patients with limited respiratory function. The solution in such cases is the utilization of minimally invasive, readily available and not expensive samples, the conditions met by the detection of serological markers of $\mathrm{PcP}$ in blood specimens.
One of such markers is the component present in cell walls of many fungi, including $P$. jirovecii cysts - $(1 \rightarrow 3)$-B-D-glucan (BG). It has been shown that its level is significantly higher in serum of patients with definite or probable PcP in comparison with the colonized people, therefore positive results of BG measurements may be indicative of the requirement for antiPcP treatment (Tasaka et al. 2014). Even though this assay is not specific for Pneumocystis, it may serve as an additional confirming tool in situations when detection by PCR does not give clear results. All available elements $-\mathrm{CD} 4+\mathrm{T}$ cell counts, symptoms, and CT findings - have still to be considered during making clinical decision and BG levels alone cannot be the proof of PcP, because of the non-specificity of this test. However, its negative predictive value $(99.8 \%$ ) can actually exclude PcP which is suitable in patients who cannot undergo bronchoscopy or in those with low clinical suspicion of PcP (Held et al. 2010). The analyses have demonstrated that positive BG and PCR results allowed applying an anti-PcP treatment in the microscopically negative patients, thus increasing the survival rate (Matsumura et al. 2014).

It has been deduced that, in complementation to PCR, BG measurements are significant for discrimination between $\mathrm{PcP}$ and colonization (Esteves et al. 2014). Different values for detection have been proposed: Salerno et al. (2014) suggested the cutoff of $300 \mathrm{pg} \mathrm{ml}^{-1}$ for the diagnosis in AIDS-positive patients, whereas Tasaka et al. (2014) estimated the cutoff level for discrimination of $33.5 \mathrm{pg} \mathrm{ml}^{-1}$. In turn, Esteves et al. (2014) have shown that the highest level of median BG was observed in samples taken from PcP patients $\left(270 \mathrm{pg} \mathrm{ml}^{-1}\right)$, followed by colonized people with almost four times lower results $\left(67 \mathrm{pg} \mathrm{ml}^{-1}\right)$, while patients with other pulmonary diseases had the lowest BG level $\left(36 \mathrm{pg} \mathrm{ml}^{-1}\right)$, almost equal to that of healthy people $\left(31 \mathrm{pg} \mathrm{ml}^{-1}\right)$.

Moreover, it has been observed that lactate dehydrogenase (LDH) serum levels are also increased in PcP patients samples. This enzyme is released from host cells in response to their cytoplasmic membrane damage, in this case probably caused by lung damage following the pathogen presence (Esteves et al. 2014). In healthy people, LDH levels are within the range of 100-350 U l $~^{-1}$. LDH levels cannot, however, be used to distinguish between $P$. jirovecii colonization and PcP, because they are too similar within the samples of these two groups of patients (Esteves et al. 2014). After all, BG and LDH levels are positively correlated; therefore, they can be used together as an adjunctive reliability factor during setting diagnosis concerning PcP (Esteves et al. 2014; Borstnar et al. 2013).

Another non-invasive approach to diagnose PcP is the utilization of enzyme-linked immunosorbent assay (ELISA). One of the relevant target proteins is the major surface glycoprotein (Msg) of Pneumocystis, the protein involved in interactions with many host molecules and in attachment to alveolar epithelial cells (Stringer and Keely 2001). The carboxyterminal region of this protein is relatively conserved, and 
antibodies directed to this fragment have been shown to be at higher level in samples taken from HIV patients with active PcP than from patients with pneumonia caused by other factors (Djawe et al. 2010b). Another important target protein for immunochemical detection is the Pneumocystis protease, kexin (Kex), encoded by a single-copy gene (Kutty and Kovacs 2003). It has been shown that even low quantities of Kex antibody level were correlated with subsequent episodes of PcP, suggesting that it may be another, early marker of future PcP risk in HIV-positive individuals (Gingo et al. 2011).

\section{Treatment}

As it was mentioned before, Pneumocystis infection cannot be treated with typical drugs utilized in fungal infections. Instead, the mechanism of disrupting folic acid pathway in Pneumocystis organisms is a good target for therapeutic agents - such therapy relies on the fact that $P$. jirovecii can not acquire folic acid from the environment, making it utterly dependent on de novo synthesis. Folic acid is required for synthesis of purines, glycine, and thymidylate-necessary for proper organism functioning. Metabolic pathway of this synthesis involves two enzymes important in anti-PcP prophylaxis-dihydropteroate synthase (DHPS) and dihydrofolate reductase (DHFR) (Volpe et al. 1993). Such prophylaxis consists of the combination of trimethoprim (TMP; an inhibitor of DHFR) and a sulfa drug, sulphamethoxazole (SMX; an inhibitor of DHPS) (Lobo et al. 2013). The inhibition of folic acid synthesis leads to the inability of production of proteins due to the lack of amino acids, as well as to impossibility of DNA synthesis and repair, because of nucleotides deficiency.

Studies performed on pathogens isolated form patients who failed sulfa drugs prophylaxis have demonstrated that characteristic non-synonymous mutations occur frequently in DHPS gene, leading to alterations in the enzyme's structure and hence reduced affinity to sulfa drugs (Armstrong et al. 2000). Such resistance occurs as a result of sulfa drug treatment employment in many other disorders, which triggers the positive selective pressure on the DHPS gene in Pneumocystis strains (Kazanjian et al. 1998). Anyhow, TMP-SMX is the most frequently used anti-Pneumocystis therapy. Moreover, it has been shown that the addition of low doses of caspofungin (caspofungin acetate, active against cysts) which acts as an inhibitor of the $(1 \rightarrow 3)$-B-D-glucan synthase, to TMP-SMX (active against cysts and trophic forms) may enhance the inhibition effect (Lobo et al. 2013). The therapy consisting of the TMP-SMX/caspofungin provides fast action, and it is more effective than with utilizing these drugs alone, due to the simultaneous fungistatic and fungicidal effect, both on cysts and trophic forms of pathogen. Moreover, this drug combination may reduce harmful inflammatory response induced by BG (Lobo et al. 2013).

\section{Prevention of PcP}

Although PcP prophylaxis for susceptible, immunocompromised patients has become the standard of care, the optimal scheme and duration of therapy have not been defined. In case of organ recipients, the early post-transplant period is the considered highest risk time for infection, albeit there is a growing evidence of late PcP recognition, even above one year after transplantation (Wu et al. 2012). In turn, in HIV-infected patients whose CD4+ T lymphocyte counts fall below critical level or in those with previous episodes of PcP, prophylaxis is advisable and it should be continued until CD4+ T cell level rises again above 200/ $\mu$ l, due to HAART therapy (From the Centers for Disease Control 1992).

Nonetheless, it has been confirmed that clinical centers undertake to perform PcP prophylaxis, among others in children with cancers (Caselli et al. 2014), resulting in effective protection of patients. Non-adherence to this prophylaxis remains the only reason for its failure; therefore, a simpler regimen with a shorter duration may be expected to improve the effectiveness. It has been suggested that a single-day prophylactic scheme with TMP-SMX may be efficient in preventing $\mathrm{PcP}$ in children with solid tumor, leukemia, or lymphoma, treated with intensive chemotherapy. This strategy may be also of potential application in other patient populations with immunosuppression (Caselli et al. 2014).

\section{Conclusions}

Due to the development of our knowledge about complications associated with HIV infection, as well as subsequent introduction of HAART therapy, it has been possible to reduce the mortality and morbidity caused by PcP among patients infected with this virus. However, despite the utilization of anti-Pneumocystis prophylaxis, this disease is still a serious public health problem, affecting mainly non-HIV patients being under immunosupression. In addition to that, many healthy, immunocompetent people are colonized with this fungus without any symptoms, therefore without the awareness of the possibility of participating in pathogen transmission to susceptible hosts. Apparently, the majority of infants are also members of colonized population. Hence, $P$. jirovecii carriage is assumed to contribute to some respiratory disorders. From all the evidence given above, it is clear that sensitive methods for detection of this fungus, as well as for distinguishing PcP from asymptomatic colonization, are essential in order to increase the survival rate of vulnerable patients. The lack of appropriate system for culturing $P$. jirovecii 
is the major impediment in research enabling expanding our knowledge about this organism, which can be instead bypassed by more specific molecular studies, including research on Pneumocystis epidemiology.

Open Access This article is distributed under the terms of the Creative Commons Attribution 4.0 International License (http:// creativecommons.org/licenses/by/4.0/), which permits unrestricted use, distribution, and reproduction in any medium, provided you give appropriate credit to the original author(s) and the source, provide a link to the Creative Commons license, and indicate if changes were made.

\section{References}

Alanio A, Desoubeaux G, Sarfati C, Hamane S, Bergeron A, Azoulay E, Molina JM, Derouin F, Menotti J (2011) Real-time PCR assay-based strategy for differentiation between active Pneumocystis jirovecii pneumonia and colonization in immunocompromised patients. Clin Microbiol Infect 17:1531-1537

Aliouat EM, Mazars E, Dei-Cas E, Delcourt P, Billaut P, Camus D (1994) Pneumocystis cross infection experiments using SCID mice and nude rats as recipient host, showed stronghost-species specificity. J Eukaryot Microbiol 41:71S

Aliouat-Denis C-M, Chabé M, Demanche C, Aliouat EM, Viscogliosi E, Guillot J, Delhaes L, Dei-Cas E (2008) Pneumocystis species, coevolution and pathogenic power. Infect Genet Evol 8:708-726

Alvarez-Martínez MJ, Miró JM, Valls ME et al (2006) Sensitivity and specificity of nested and real-time PCR for the detection of Pneumocystis jiroveci in clinical specimens. Diagn Microbiol Infect Dis 56:153-160

Armstrong W, Meshnick S, Kazanjian P (2000) Pneumocystis carinii mutations associated with sulfa and sulfone prophylaxis failures in immunocompromised patients. Microbes Infect 2:61-67

Barry S, Johnson M (2001) Pneumocystis carinii pneumonia: a review of current issues in diagnosis and management. HIV Med 2:123-132

Beard CB, Carter JL, Keely SP et al (2000) Genetic variations in Pneumocystis carinii isolates from different geographic regions: implications for transmission. Emerg Infect Dis 6:265-272

Bento DP, Esteves F, Matos O, Miranda AC, Ventura F, Araújo C, Mansinho K (2013) Unusual coexistence of opportunistic lung infections in a human immunodeficiency virus positive patient suffering from persistent Pneumocystis jirovecii pneumonia: a case report. Rev Port Pneumol 19:129-133

Borstnar S, Lindic J, Tomazic J, Kandus A, Pikelj A, Prah J, Skvarc M, Godunov U, Kovac D (2013) Pneumocystis jirovecii pneumonia in renal transplant recipients: a national center experience. Transpl Proc 45:1614-1617

Caselli D, Petris MG, Rondelli R et al (2014) Single-day trimethoprim/ sulfamethoxazole prophylaxis for Pneumocystis pneumonia in children with cancer. J Pediatr 164:389-392

De Boer MGJ, Kroon FP, le Cessie S, de Fijter JW, van Dissel JT (2011) Risk factors for Pneumocystis jirovecii pneumonia in kidney transplant recipients and appraisal of strategies for selective use of chemoprophylaxis. Transpl Infect Dis 13:559-569

Dęborska-Materkowska D, Kozińska-Przybył O, MikaszewskaSokolewicz M, Durlik M (2014) Fatal late-onset Pneumocystis pneumonia after rituximab: administration for posttransplantation recurrence of focal segmental glomerulosclerosis-case report. Transpl Proc 46:2908-2911

Dimonte S, Berrilli F, D'Orazi C, D'Alfonso R, Placco F, Bordi E, Perno CF, Di Cave D (2013) Molecular analysis based on $m t L S U-r R N A$ and DHPS sequences of Pneumocystis jirovecii from immunocompromised and immunocompetent patients in Italy. Infect Genet Evol 14:68-72

Djawe K, Daly KR, Vargas SL, Santolaya ME, Ponce CA, Bustamante R, Koch J, Levin L, Walzer PD (2010a) Seroepidemiological study of Pneumocystis jirovecii infection in healthy infants in Chile using recombinant fragments of the $P$. jirovecii major surface glycoprotein. Int J Infect Dis 14:e1060-1066

Djawe K, Huang L, Daly KR et al (2010b) Serum antibody levels to the Pneumocystis jirovecii major surface glycoprotein in the diagnosis of $P$. jirovecii pneumonia in HIV+ patients. PloS One 5:e14259

Dumoulin A, Mazars E, Seguy N, Gargallo-Viola D, Vargas S, Cailliez JC, Aliouat EM, Wakefield AE, Dei-Cas E (2000) Transmission of Pneumocystis carinii disease from immunocompetent contacts of infected hosts to susceptible hosts. Eur J Clin Microbiol Infect Dis 19:671-678

Edman JC, Kovacs JA, Masur H, Santi DV, Elwood HJ, Sogin ML (1988) Ribosomal RNA sequence shows Pneumocystis carinii to be a member of the fungi. Nature 334:519-522

Esteves F, Montes-Cano MA, de la Horra C, Costa MC, Calderón EJ, Antunes F, Matos O (2008) Pneumocystis jirovecii multilocus genotyping profiles in patients from Portugal and Spain. Clin Microbiol Infect 14:356-362

Esteves F, Gaspar J, De Sousa B, Antunes F, Mansinho K, Matos O (2011) Clinical relevance of multiple single-nucleotide polymorphisms in Pneumocystis jirovecii pneumonia: development of a multiplex PCR-single-base-extension methodology. J Clin Microbiol 49:1810-1815

Esteves F, Lee C-H, De Sousa B, Badura R, Seringa M, Fernandes C, Gaspar JF, Antunes F, Matos O (2014) $(1 \rightarrow 3) \beta$-D-glucan in association with lactate dehydrogenase as biomarkers of Pneumocystis pneumonia $(\mathrm{PcP})$ in $\mathrm{HIV}$-infected patients. Eur J Clin Microbiol Infect Dis 33:1173-1180

Frenkel JK (1999) Pneumocystis pneumonia, an immunodeficiencydependent disease (IDD): a critical historical overview. J Eukaryot Microbiol 46:89-92

From the Centers for Disease Control (1992) Recommendations for prophylaxis against Pneumocystis carinii pneumonia for adults and adolescents infected with HIV [published erratum appears in JAMA 1992; 268: 55]. JAMA 267:2294-2296

Gigliotti F, Harmsen AG, Wright TW (2003) Characterization of transmission of Pneumocystis carinii f. sp. muris through immunocompetent BALB/c mice. Infect Immun 71:3852-3856

Gingo MR, Lucht L, Daly KR et al (2011) Serologic responses to Pneumocystis proteins in HIV patients with and without Pneumocystis jirovecii pneumonia. JAIDS 57:190-196

Held J, Koch MS, Reischl U, Danner T, Serr A (2010) Serum $(1 \rightarrow 3) \beta$ D-glucan measurement as an early indicator of Pneumocystis jirovecii pneumonia and evaluation of its prognostic value. Clin Microbiol Infect 17:595-602

Kaneshiro ES, Ellis JE, Jayasimhulu K, Beach DH (1994) Evidence for the presence of "metabolic sterols" in Pneumocystis: identification and initial characterization of Pneumocystis carinii sterols. J Eukaryot Microbiol 41:78-85

Kaplan JE, Hanson D, Dworkin MS, Frederick T, Bertolli J, Lindegren ML, Holmberg S, Jones JL (2000) Epidemiology of human immunodeficiency virus-associated opportunistic infections in the United States in the Era of highly active antiretroviral therapy. Clin Infect Dis 30:5-14

Kazanjian P, Locke AB, Hossler PA, Lane BR, Bartlett MS, Smith JW, Cannon M, Meschnick S (1998) Pneumocystis carinii mutations associated with sulfa and sulfone prophylaxis failures in AIDS patients. AIDS 12:873-878

Keely SP, Stringer JR, Baughman RP, Linke MJ, Walzer PD, Smulian GA (1995) Genetic variation among Pneumocystis carinii hominis isolates in recurrent pneumocystosis. J Infect Dis 172:595-598 
Kim SJ, Lee J, Cho Y-J et al (2014) Prognostic factors of Pneumocystis jirovecii pneumonia in patients without HIV infection. J Infect 69: $88-95$

Ko Y, Jeong B-H, Park HY, Koh W-J, Suh GY, Chung MP, Kwon OJ, Jeon K (2014) Outcomes of Pneumocystis pneumonia with respiratory failure in HIV-negative patients. J Crit Care 29:356-61

Kofteridis DP, Valachis A, Velegraki M, Antoniou M, Christofaki M, Vrentzos GE, Andrianaki AM, Samonis G (2014) Predisposing factors, clinical characteristics and outcome of Pneumonocystis jirovecii pneumonia in HIV-negative patients. J Infect Chemother 20:412-416

Kutty G, Kovacs JA (2003) A single-copy gene encodes Kex1, a serine endoprotease of Pneumocystis jiroveci. Infect Immun 71:571-574

Li M-C, Lee N-Y, Lee C-C, Lee H-C, Chang C-M, Ko W-C (2014) Pneumocystis jiroveci pneumonia in immunocompromised patients: delayed diagnosis and poor outcomes in non-HIV-infected individuals. J Microbiol Immunol Infect 47:42-47

Limper AH, Thomas CF (2007) Current insights into the biology and pathogenesis of Pneumocystis pneumonia. Nat Rev Microbiol 5: 298-308

Limper AH, Offord KR, Smith TF, Martin WJ II (1989) Differences in the lung parasite number and inflammation in patients with and without AIDS. Am Rev Respir Dis 140:1204-1209

Lobo ML, Esteves F, De Sousa B, Cardoso F, Cushion MT, Antunes F, Matos O (2013) Therapeutic potential of caspofungin combined with trimethoprim-sulfamethoxazole for Pneumocystis pneumonia: a pilot study in mice. PloS One 8:e70619

Maitte C, Leterrier M, Le Pape P, Miegeville M, Morio F (2013) Multilocus sequence typing of Pneumocystis jirovecii from clinical samples: how many and which loci should be used? J Clin Microbiol 51:2843-2849

Matsumura Y, Ito Y, Yamamoto M, Matsushima A, Nagao M, Takakura S, Iinuma Y, Ichiyama S (2014) Pneumocystis polymerase chain reaction and blood $(1 \rightarrow 3)$ - $\beta$-D-glucan assays to predict survival with suspected Pneumocystis jirovecii pneumonia. J Infect Chemother 20:109-114

Monnet X, Vidal-Petiot E, Osman D, Hamzaoui O, Durrbach A, Goujard C, Miceli C, Bourée P, Richard C (2008) Critical care management and outcome of severe Pneumocystis pneumonia in patients with and without HIV infection. Crit Care 12:R28

Monroy-Vaca EX, de Armas Y, Illnait-Zaragozí MT, Diaz R, Toraño G, Vega D, Álvarez-Lam I, Calderón EJ, Stensvold CR (2014) Genetic diversity of Pneumocystis jirovecii in colonized Cuban infants and toddlers. Infect Genet Evol 22:60-66

Nahimana A, Rabodonirina M, Bille J, Francioli P, Hauser PM (2004) Mutations of Pneumocystis jirovecii dihydrofolate reductase associated with failure of prophylaxis. Antimicrob Agents Chemother 48: 4301-4305

Peterson JC, Cushion MT (2005) Pneumocystis: not just pneumonia. Curr Opin Microbiol 8:393-398

Phair J, Munoz A, Detels R, Kaslow R, Rinaldo C, Saah A (1990) The risk of Pneumocystis carinii pneumonia among men infected with human immunodeficiency virus type 1. N Engl J Med 322:161-165

Piffer L, Hughes WT, Stagno S, Woods D (1978) Pneumocystis carinii infection: evidence for high prevalence in normal and immunosuppressed children. Pediatrics 61:35-41

Probst M, Ries H, Schmidt-Wieland T, Serr A (2000) Detection of Pneumocystis carinii DNA in patients with chronic lung diseases. Eur J Clin Microbiol Infect Dis 19:644-645

Rivero L, de la Horra C, Montes-Cano MA et al (2008) Pneumocystis jirovecii transmission from immunocompetent carriers to infant. Emerg Infect Dis 14:1116-1118

Roblot F, Godet C, Le Moal G et al (2002) Analysis of underlying diseases and prognosis factors associated with Pneumocystis carinii pneumonia in immunocompromised HIV-negative patients. Eur J Clin Microbiol Infect Dis 21:523-531

Roux A, Canet E, Valade S et al (2014) Pneumocystis jirovecii pneumonia in patients with or without AIDS, France. Emerg Infect Dis 20: 1490-1497

Salerno D, Mushatt D, Myers L, Zhuang Y, de la Rua N, Calderon EJ, Welsh DA (2014) Serum and bal beta-D-glucan for the diagnosis of Pneumocystis pneumonia in HIV positive patients. Respir Med 108: $1688-1695$

Selik RM, Starcher ET, Curran JW (1987) Opportunistic diseases reported in AIDS patients: frequencies, associations, and trends. AIDS 1: $175-182$

Spencer L, Ukwu M, Alexander T, Valadez K, Liu L, Kovacs A, Morris A (2009) Epidemiology of Pneumocystis colonization in families. Clin Infect Dis 46:1237-1240

Stapleton RD, Wang BM, Caldwell ES, Steinberg KP (2015) Causes and timing of death in patients with ARDS. Chest 128:525-532

Stringer JR (2002) Pneumocystis. Int J Med Microbiol 292:391-404

Stringer JR, Keely SP (2001) Genetics of surface antigen expression in Pneumocystis carinii. Infect Immun 69:627-639

Tasaka S, Kobayashi S, Yagi K, Asami T, Namkoong H, Yamasawa W, Ishii M, Hasegawa N, Betsuyaku T (2014) Serum $(1 \rightarrow 3) \beta$-D-glucan assay for discrimination between Pneumocystis jirovecii pneumonia and colonization. J Infect Chemother 20:678-681

Totet A, Latouche S, Lacube P, Pautard J, Jounieaux V, Raccurt C, Roux $P$, Nevez G (2004) Dihydropteroate synthase genotypes in immunocompetent infants and immunosuppressed adults, Amiens, France. Emerg Infect Dis 10:667-673

Vargas SL, Hughes WT, Santolaya ME, Ulloa AV, Ponce CA, Cabrera CE, Cumsille F, Gigliotti F (2001) Search for primary infection by Pneumocystis carinii in a cohort of normal, healthy infants. Clin Infect Dis 32:855-861

Vargas SL, Ponce CA, Sanchez CA, Ulloa AV, Bustamante R, Juarez G (2003) Pregnancy and asymptomatic carriage of Pneumocystis jiroveci. Emerg Infect Dis 9:605-606

Vargas SL, Ponce CA, Gálvez P, Ibarra C, Haas EA, Chadwick AE, Krous HF (2007) Pneumocystis is not a direct cause of sudden infant death syndrome. Pediatr Infect Dis J 26:81-83

Vargas SL, Ponce CA, Gallo M et al (2013) Near-universal prevalence of Pneumocystis and associated increase in mucus in the lungs of infants with sudden unexpected death. Clin Infect Dis 56:171-179

Vogel MN, Vatlach M, Weissgerber P, Goeppert B, Claussen CD, Hetzel J, Horger M (2012) HRCT-features of Pneumocystis jiroveci pneumonia and their evolution before and after treatment in non-HIV immunocompromised patients. Eur J Radiol 81:1315-1320

Volpe F, Ballantine SP, Delves CJ (1993) The multifunctional folic acid synthesis fas gene of Pneumocystis carinii encodes dihydroneopterin aldolase, hydroxymethyldihydropterin pyrophosphokinase and dihydropteroate synthase. Eur J Biochem 216:449-458

Wakefield AE, Lindley AR, Ambrose HE, Denis CM, Miller RF (2003) Limited asymptomatic carriage of Pneumocystis jiroveci in human immunodeficiency virus-infected patients. J Infect Dis 187:901-908

Walzer PD, Schultz MG, Western KA, Robbins JF (1976) Pneumocystis carinii pneumonia and primary immune deficiency diseases. Natl Cancer Inst Monogr 43:65-74

Ward MM, Donald F (1999) Pneumocystis carinii pneumonia in patients with connective tissue diseases: the role of hospital experience in diagnosis and mortality. Arthritis Rheum 42:780-789

Wu Y-S, Lin N-C, Chen L-M, Chang S-C, Wang F-D, Huang Y-C, Wu TH, Loong C-C (2012) Extracorporeal membrane oxygenation as treatment for acute respiratory failure and subsequent pneumothorax caused by Pneumocystis jirovecii pneumonia in a kidney transplant recipient. Transpl Infect Dis 15:E5-E8 